\title{
Numerical Modelling of Inclined Piles in Settling Soil
}

\author{
Anders Beijer Lundberg ${ }^{1}$, Fredrik Resare ${ }^{2}$, Gary Axelsson ${ }^{3}$ \\ ELU Konsult AB, Sweden \\ E-mails: 'Ianders.beijer@elu.se (corresponding author); ${ }^{2}$ fredrik.resare@elu.se; ${ }^{3}$ gary.axelsson@elu.se
}

\begin{abstract}
The allowable load for slender end-bearing piles in soft soils driven or drilled to compact till or rock frequently depends on the structural capacity of the pile. Pile groups consisting of such slender preceast concrete or steel piles often include inclined piles, since such small-diameter piles have a limited horizontal bearing capacity. Inclined piles placed in settling soil are subjected to a lateral force, which reduces the pile structural capacity. The simplified beam-spring design methods normally used to predict the impact on the structural capacity of inclined piles in settling soil are currently very crude because of the simplified description of the real pile and soil. On the other hand, the possibility to accurately calculate settlements in soft soil is highly developed, and it is possible to include creep effects in routine settlement calculations. There is currently no direct link between the advanced settlement analysis and the crude beam-spring idealization of inclined piles in settling soil. A full numerical model containing both the pile soilstructure interaction and the settlement process is very time-consuming to run and associated with mesh convergence and contact formulation problems. Herein a suitable modelling idealization of the settling soil is discussed, in which a settlement distribution from an advanced FEM-analysis is adapted to a simplified FEM or beam spring analysis suitable for practical design. The calculation method is compared to field measurements, and is shown to compare well with the field case. A strategy to adapt the settlement profile to model calculation of inclined piles is discussed.
\end{abstract}

Keywords: piles, creep settlements, numerical modelling, FEM, FEA.

Conference topic: Design experiences and theoretical solutions.

\section{Introduction}

Piles constitute the mechanical interface between a superstructure and the ground. An analysis of the geotechnical and structural capacity of a pile group is carried out in practical design through an assessment of the soil properties and the subsequent detailed mechanical analysis of the bearing capacity of the designed structures. The soft Scandinavian clays typically exhibit very large settlements as a result of changes in effective stress or disturbance of the soil. These effective stress changes can occur through a lowering of the water table, placing of surcharge fill, or other construction or environmental activities close the structures. Such settlements are longterm processes that need to be taken into account in practical design. The design of inclined piles is here analyzed, and a suitable method to conduct numerical simulations is discussed in some detail.

\section{Methodology}

The practical design of inclined piles in settling soil is examined in three steps. The use and current design methods of inclined piles in settling soil in Sweden is elaborated, and the limitations of the calculations methods are discussed. The soil settlement process is then examined, and the use of advanced numerical models for long-term settlement including creep is assessed through a field test case of a test embankment on soft clay in which a scenario analysis is carried out to exhibit the possbility to conduct sensitivity analysis in practical design. Finally, a 3D-FEM calculation method is presented which uses the soil settlement profile from the advanced numerical settlement models as input. The proposed model is shown to compare well with field measurements, and constitute a suitable tool for analysis in practical design.

\section{The use of inclined piles}

Slender end-bearing steel and concrete piles are frequently used in Sweden because of the very soft clay which is frequently found in the top part of the soil strata. Such piles are driven to refusal or drilled into rock. The geotechnical bearing-capacity of such piles is commonly assessed with dynamic pile load tests, and analyzed with the CASE or CAPWAP method (Gravare et al. 1980). The pile-end bearing capacity is often very large as a result of the hard rock and firm bottom till layers. The structural bearing capacity consequently often limits the allowable pile load, and as a result forms an important part of practical pile design.

The structural bearing capacity of vertical piles is the minimum value of the pile material strength or the pile bucking resistance. The buckling resistance depends on the initial culvature of the pile, and the properties of the pile material. A full description of the calculation model idealization for vertical piles is found in Wennerstrand and Fredriksson (1989). Such calculation models for vertical piles have been proven to be robust and are routinely used in design. The frequent use of inclined piles is however a source of some concern, and is therefore discussed in some detail.

Pile groups are often subjected to horizontal loads, e.g. from eccentric static loads and wind and traffic loads. Due to the small diameter of the slender precast 
concrete or steel piles frequently used in Sweden and the presence of soft upper soil layers, inclined piles are commonly included in pile groups in order to counteract the horizontal loads. The piles are often inclined with a maximum of angle of $4: 1$ relative the vertical axis. Many other countries use the horizontal capacity of large diameter drilled piles to counteract these forces, (Tomlinson, Boorman 2001), but due to the geological conditions previously mentioned, inclined slender piles are normally used in Swedish soils.

\section{Soil settlements around inclined piles}

The risk of significant soil settlement influences the bearing capacity of the inclined piles. Scandinavian soft clays are prone to large settlements, (Bjerrum 1967). Such settlements are a common feature of geotechnical and structural design, and may be caused by changes in effective stress conditions, e.g. from fill surrounding the pile group or possible lowering of the groundwater table in the area. The soil settlements frequently occur over long time-spans, with a significant settlement rate observed even after 40-50 years, (Larsson 2006).

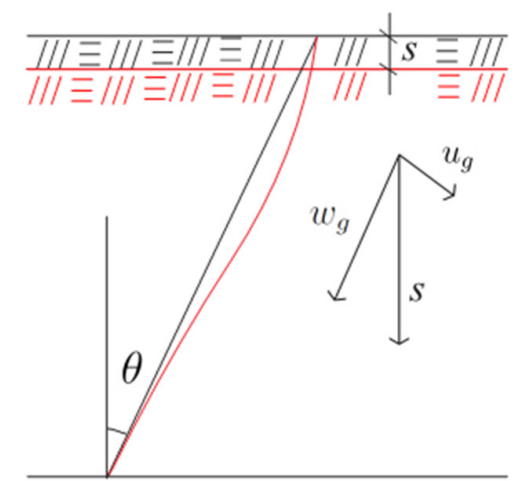

Fig. 1. Deflection of an inclined pile in settling soil

Settlements influence the performance of piles structure: negative skin friction and dragload occur in vertical piles, (Johannessen, Bjerrum 1965). Inclined piles are also subjected to the gravity load of the soil resulting from the settlement of the soil surrounding the pile. This distributed load causes bending of the pile, which reduces the structural bearing capacity of the pile. The lateral deflection of the pile $u_{g}$, resulting from the settlement $s$ for a pile with the inclination $\theta$, is shown in Figure 1.

The possibility of reduced bearing capacity of inclined piles is therefore a source of concern that should be assessed in practical design. An alternative would be to equip the structure with some other lateral restraint, (Tomlinson, Boorman 2001). There are however not many practical alternatives to inclined slender piles in Sweden due to the frequent occurence of very soft soil that prohibit the use of vertical piles. Inclined piles are therefore widely used in Sweden, and the reduction in the structural bearing capacity resulting from possible soil settlement is designed through the calculation of the extra moment in the pile, (Broms et al. 1976).

\section{Current calculation models}

Currently the influence on inclined piles from settling soils is calculated by a beam-spring model, in which the pile is modelled as an elastic beam on an elasto-plastic medium, (Svahn, Alén 2006). The governing differential equation of the pile depends on the difference in horizontal displacement between the pile and the soil, shown in Figure 2. The soil is modelled as perfectly plastic p-y curves, consisting of a formulation of the spring stiffness, limit stress at plastic yield, and lateral displacement at plastic yield, following the model of laterally loaded piles presented in Reese et al. (1974). The soil settlement is estimated and imposed as a horizontal displacement of the pile.

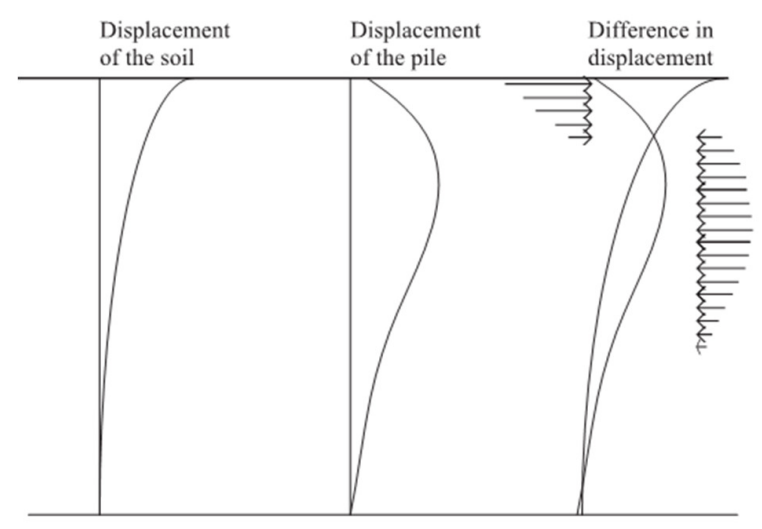

Fig. 2. The difference in displacement between the pile and the soil, resulting in an induced bending moment in the pile

\section{Numerical assessment of pile soil-structure interac- tion during soil settlement}

The standard beam-spring model contains large simplifications of the real inclined pile, and is therefore relatively crude and not suitable for advanced analysis of parameter variation, (Svahn, Alén 2006). In order to evaluate the accuracy of the beam spring model and to provide a more realistic description of the pile soil interaction, a full 3D-model would be preferred. The advantage of such a model is the possibility to conduct a full parameter study, which means that the different design situations would be modelled in full detail and a sensitivity analysis of the life-cycle stability of the structure can be carried out, something that is not possible in the simplified model.

The numerical implementation of such a model is however not straight-forward: The available soil models that are describing long-term soil settlement are relatively complicated in their formulation and require relatively large computational power for a full consolidation analysis in 3D, (Jostad, Degago 2010). The inclined pile needs to be modelled in 3D, since there is no symmetry along the gravitational axis, which means that an ax- 
isymmetric model is not suitable. The interaction between the soil and the pile also results in contactinteraction and large deformation problems that need to be handled in the numerical model.

Due to these constraints, it is not feasible to use a complete soil-structure model in practical design. The consideration of inclined piles in settling soil therefore requires a suitable idealization to be of practical use. As a starting point, the soil settlement needs to be considered in a realistic soil model including long-term creep effects in normally to lightly-overconsolidated soils, which is typical of Scandinavian clays.

\section{Settlement of soft Scandinavian clays}

The soft Scandinavian clays are very prone to settlements as a result of effective stress changes and disturbance, (Bjerrum 1967). The long-term settlements have in some cases exceeded $1 \mathrm{~m}$ and have also occurred over long time periods, (Larsson 2006).

Design and risk-analysis of structures built in such soft clays is therefore complicated, but the calculation process during design is greatly assisted by advanced numerical simulations, in which long-term effects can be estimated. Such numerical simulations are controlled by idealized material models of the stress-strain response of the soil. These models do however display a large variation in computed deformations, depending on the model configuration and soil parameters, (Jostad, Degago 2010). A robust design strategy is therefore to conduct a series of sensitivity analyses including parameter variation, to assess the sensitivity of the soil parameters and boundary conditions. This results in a scenario analysis, which is heavily dependent on the bias of the particular soil model used in design. Possible design scenarios include the lowering of the groundwater table in the area surrounding the structure, extra surcharge load and traffic load, as well as disturbance from future construction activities, e.g. pile driving or excavation close to the soil structure. A possible such scenario is later described in some detail.

\section{An assessment of available creep models}

Numerical models, e.g. implemented in FEM, can perform detailed analysis of the stress-strain response of the soil and thereby the deformation and settlement process. A suitable material model concerning the longterm behaviour of the clay soil is essential for accurate prediction of the settlement of the soil. Many soil models have been developed for calculation of the long-term stress strain behaviour, (Jostad, Degago 2010). Most of the models consist of an elasto-plastic framework which incorporates the isotache concept, (Šuklje 1957), in which the vertical creep strain is described as:

$$
\frac{\delta \varepsilon_{\text {creep }}}{\delta t}=\frac{1}{R},
$$

where: $\varepsilon_{\text {creep }}$ is the vertical creep strain, $t$ is the time and $R$ is Janbu's time resistance, (Janbu 1969), and

$$
R=R_{i}+r \cdot t
$$

where: $R_{i}$ is the initial time resistance and $r$ is the timeresistance number.

The total settlement including consolidation and creep can then be described in one dimension:

$$
\frac{\delta \varepsilon_{v}}{\delta t}=\frac{1}{M_{t}} \frac{\delta \sigma_{v}^{\prime}}{\delta t}+\frac{1}{R},
$$

where: $\varepsilon_{v}$ is the vertical strain, $M_{t}$ is the constrained (one-dimensional) deformation modulus and $\sigma_{v}{ }^{\prime}$ is the effective vertical stress. The constrained deformation modulus $M_{t}$ varies with the effective stress level $\sigma_{v}$ ', which needs to be included in the numerical model.

Material models for simulation of long-term settlements in 3D stress space have also be formulated, e.g. Vermeer, Neher (1999).

\section{Calculating creep settlement in design}

Numerical calculation of long-term creep settlements are routinely carried out in design by some of the proposed soil models, (Jostad, Degago 2010). A finite element model (FEM) is often used in order to realise the numerical calculations in one dimension. The soil models typically consist of an elasto-plastic model with a hardening or softening formulation for yield. A viscoplastic component is added to simulate the long-term creep volumetric behaviour of the soil with the isotache type of model, along the model of Šulkje, 1957 in Equations 1 and 2. The one-dimensional models are however frequently used in practical design, and have been shown to produce relatively robust simulation of longterm settlements, (Larsson 2006). Next, a scenario analysis is shown as an example of the use of settlement calculations.

\section{Sensitivity analysis: Ska-edeby}

The possibility the estimate the long-term settlements of soft Scandinavian clay is here displayed by the case of a test embankment, (Larsson 2006). The soil consists of soft clay with a dry crust by the ground surface. Figure 3 displays a simulation of the long-term settlement carried out by a one-dimensional numerical model using field data described in Larsson (2006). The simulated settlements are shown to be relatively large, and would certainly have a significant influence on any piles located nearby. To assess the effects of lowering of the ground water table, as well as the possibility of placing of surcharge load, simulations described in Table 1 werecarried out. These display the settlements that may be expected, which are shown to be relatively large. A much more extensive sensitivity analysis is obviously possible, but this example highlights the possibility to use numerical analysis for long-term settlement analysis. 


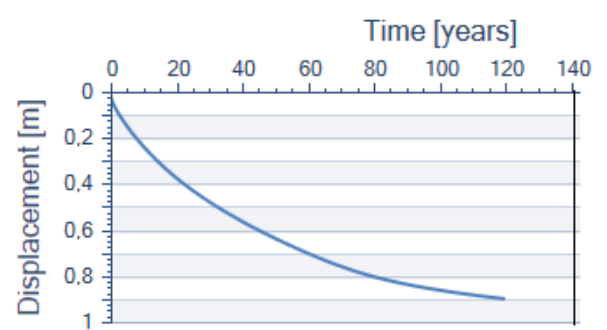

Fig. 3. Simulation of the long-term settlement at Ska-Edeby in the 1D FEM-model

Table 1 . The results of the numerical sensitivity analysis

\begin{tabular}{l|c}
\hline \multicolumn{1}{c|}{ Scenario } & Calculation settlement $(\mathrm{m})$ \\
\hline $\begin{array}{l}\text { Constant load, no change in ground } \\
\text { water table }\end{array}$ & 0.9 \\
$\begin{array}{l}\text { Constant load, } 1 \mathrm{~m} \text { lowering of } \\
\text { ground water table }\end{array}$ & 1.2 \\
\hline $\begin{array}{l}12 \mathrm{kPa} \text { surcharge load increase, } 1 \mathrm{~m} \\
\text { lowering of ground water table }\end{array}$ & 1.4 \\
\hline
\end{tabular}

\section{Settlement models for pile analysis in 3D}

Extending the standard one-dimensional models to 3D in practical design would be relatively cumbersome without offering large benefits in the calculations of settlements. This is however necessary to calculate the effect of soil settlements on an inclined pile, since the geometry of the practical configuration of the pile in the soil is set in $3 \mathrm{D}$. It would therefore be more useful to extend the one-dimensional numerical simulations of soil settlements to the calculation of the bearing capacity of an inclined pile instead of extending the numerical model to 3D. We should therefore study the possibility of using a one-dimensional settlement profile instead.

\section{Modelling inclined piles in consolidating soil}

A simplified numerical model is therefore presented in order to avoid including the pile in the full 3D FEM settlement model. In the current model the deformation of the soil was simulated as a stress-free settlement, resulting in a specified settlement profile. This was achieved in the program ABAQUS/Standard by including the thermal properties of the soil and imposing a thermal field that results in compressive strains without changing the stress field, (Abaqus 2001).

The numerical model was set up to replicate a field test of inclined piles supporting an embankment on soft clay, (Takahashi 1985), In the field test, $508 \mathrm{~mm}$ tubular steel piles with an inclination of $14^{\circ}$ to the vertical axis were placed in the soft clay settling underneath the embankment fill, and the deformation of the pile and the soil settlement were measured. This corresponds well with the conditions for Swedish clays and is therefore a good field case to study the use of a suitable calculation model.

The FEM model was set-up in Abaqus/Standard and the pile and soil model parameter displayed in Ta- ble 2 and 3 were used in the simulation. The soil settlement at the top of the clay layer was $250 \mathrm{~mm}$, and the soil settlement declined to around $50 \mathrm{~mm}$ at 8 meters depth, after which relatively small settlements were recorded in the underlying supporting strata. The full details of the field tests are discussed in Takahashi, 1985.

The geometry of the numerical model is shown in Figure 4. The inclined pile was modelled in halfsymmetric space. The soil was modelled with $3 \mathrm{D}$ solid elements and the pile as shell elements. The compressive strain was modelled by orthotropic temperature dependency and a temperature change along the vertical axis was created in the model, which resulted in a stress-free compressive stress. The interaction between the pile and the soil was modelled with a penalty-type interface.

Table 2. Mechanical properties of the tubular pile

\begin{tabular}{l|c}
\hline Model parameter & Model value \\
\hline Pile diameter & $508 \mathrm{~mm}$ \\
\hline Piles & $\mathrm{mm}$ \\
\hline Pile elastic modulus & $210 \mathrm{GPa}$ \\
\hline Poisson's ratio & 0.3 \\
\hline Pile length & $38.7 \mathrm{~m}$ \\
\hline
\end{tabular}

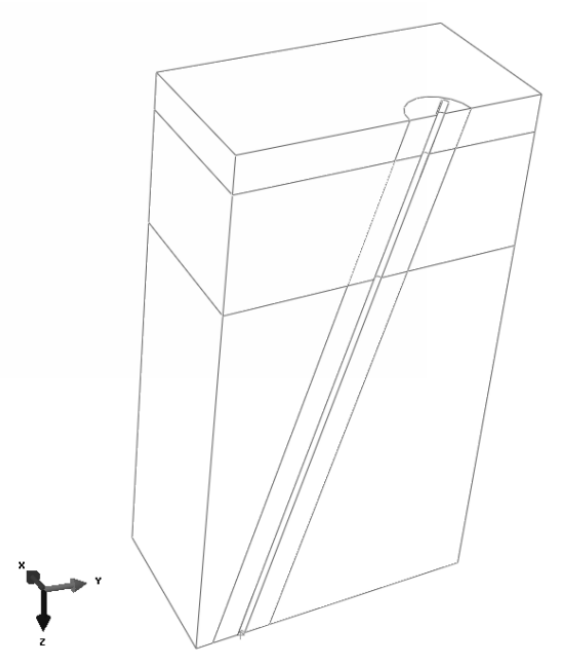

Fig. 4. Geometry of the bisymmetric numerical model.

Table 3. Mechanical properties of the soil

\begin{tabular}{l|c}
\hline Model parameter & Model value \\
\hline Weight & $17 \mathrm{kN} / \mathrm{m}^{3}$ \\
\hline Elastic modulus & $\begin{array}{c}\text { Clay: } 250 \cdot \mathrm{c}_{\mathrm{u}} \\
\text { Embankment: } 50 \mathrm{MPa}\end{array}$ \\
\hline Poisson's ratio & 0.3 \\
\hline Friction angle & $\begin{array}{c}\text { Clay: } 29^{\circ} \\
\text { Embankment: } 45^{\circ}\end{array}$ \\
\hline Dilation angle & $1^{\circ}$ \\
\hline Cohesion & $1 \mathrm{kPa}$ \\
\hline
\end{tabular}




\section{Calculation results}

The model calculation was carried out by imposing the compressive strain on the soil profile. The maximum bending moments in the pile were then sampled along the pile length and compared to the field measurements. This is shown in Figure 5. It appears that the numerical model compares relatively well to the field tests. Both the measured and calculated bending moments appear to be directly proportional to the settlement of the ground surface. The bending moments at smaller levels of ground settlement however seems to be somewhat smaller than the model simulations. The soil area around the pile that exhibits plastic yield according to the Mohr-Coulomb yield criterion is displayed in grey in Figure 6.

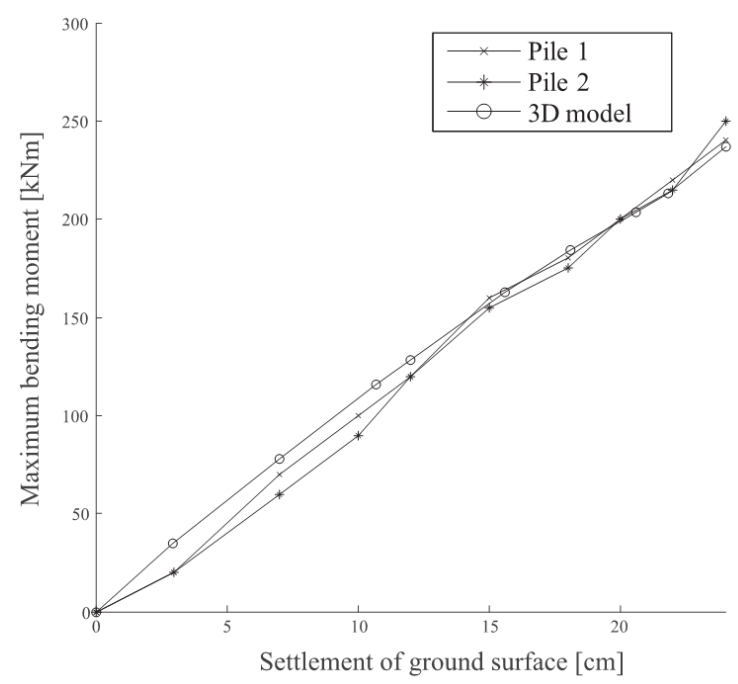

Fig. 5. The simulated maximum bending moment in the pile versus the measured bending moment

\section{Discussion}

The numerical model simulation in Figure 6 shows that the load distribution from the settling soil on the inclined piles compares well with the identified wedge and deep modes proposed by Reese et al. (1974), as shown in Figure 6. In both these yield mechanisms the soil deformation results from distortional shear stress. The proposed soil models for long-term settlements, e.g. the soft soil creep model, (Vermeer et al. 1999 would probably show a similar yield mechanism since the distortional shear strength is also formulated according to a Mohr-Coulomb model. The stress distribution around the inclined piles would possibly by slightly altered because of the consolidation and creep in the full model, but since the wedge and deep yield mechanism dominate the soil-structure interaction response, it would probably have a minor impact on the deformation and bending moment of the pile.

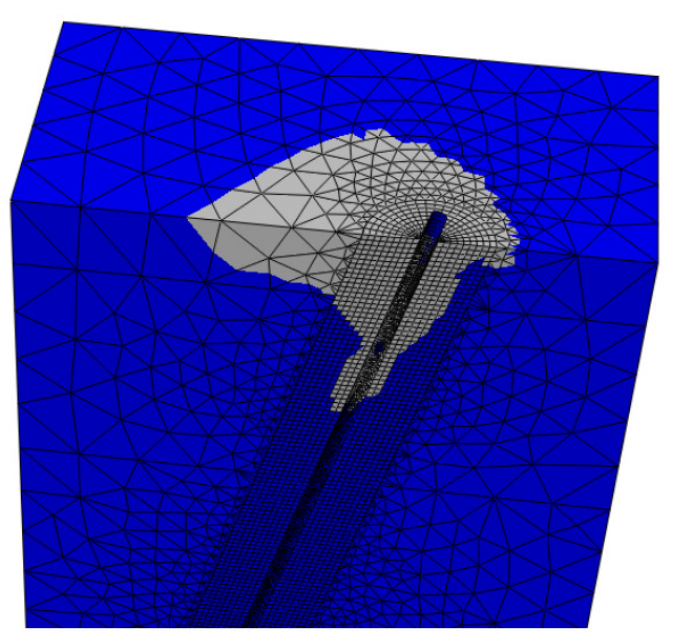

Fig. 6. An illustration of the area around that pile displaying plastic yield according to the Mohr-Coulomb criterion

\section{Conclusions}

The case of inclined piles in settling soil has been presented. The frequent use of slender inclined piles in soft soils in Scandinavia results in routine calculations of the structural bearing capacity of the pile. The calculations models used are relatively crude in comparison to the real soil-structure interaction, and a more refined model would be useful in practical design. The advanced longterm soil settlements models are however not very suitable to use in a 3D-model. The inclusion of the full pilesettling soil response in such a model would likely by complicated and result in convergence and contact formulation error, and not suitable for sensitivity analysis. A suitable design idealization for numerical modelling of inclined piles in settling soil has therefore been presented. In this procedure the soil settlement profile is calculated separately by proven soil models, and the resulting soil settlement profile is imposed on a drained Mohr-Coulomb model through stress-free compressive strain. The pile curvature and moment can then be calculated. Field measurements show that the new method gives a good representation of the field soil-structure response. The proposed method is significantly more straight-forward compared to a soil-structure interaction model in $3 \mathrm{D}$ and is therefore more suitable in design.

\section{Disclosure statement}

The authors assure that do not they have any competing financial, professional, or personal interests from other parties.

\section{References}

ABAQUS. 2001. ABAQUS user's manual, Vol. 1. Hibbitt, Karlsson \& Sorensen. 
Bjerrum, L. 1967. Engineering geology of Norwegian normally-consolidated marine clays as related to settlements of buildings, Geotechnique 17(2): 83-118. http://dx.doi.org/10.1680/geot.1967.17.2.83

Broms, B. B.; Fredriksson, A.; Carlsson, L. 1976. Land subsidence in Sweden due to water-leakage into deeplying tunnels and its effects on pile supported structures, in Second International Symposium on Land Subsidence, December 1976, Anaheim, California.

Gravare, C. J.; Goble, G. G.; Rausche, F.; Likins, G. E. 1980. Pile driving construction control by the Case method. Ground Engineering, United Kingdom.

Janbu, N. 1969. The resistance concept applied to deformations of soils, in Proceedings of the $7^{\text {th }}$ International Conference on Soil Mechanics and Foundation Engineering, 1969, Mexico City, 25-29.

Johannessen, I. J.; Bjerrum, L. 1965. Measurement of the compression of a steel pile to rock due to settlement of the surrounding clay, in Soil Mechanics and Foundation Engineering Conference Proceedings, 1965, Montreal, Canada.

Jostad, H. P.; Degago, S. A. 2010. Comparison of methods for calculation of settlements of soft clay, in T. Benz, S. Nordal (Eds.). Numerical methods in geotechnical engineering. CRC press, 57-62.

Larsson, R. 2006. Long-term observations of consolidation processes-results from about fifty years' monitoring of Swedish test embankments on soft clay, Geotechnical Engineering 37(1): 53.
Reese, L. C.; Cox, W. R.; Koop, F. D. 1974. Analysis of laterally loaded piles in sand, in Offshore Technology Conference, 6-8 May, Houston, Texas.

Šuklje, L. 1957. The analysis of the consolidation process by the isotache method, in Proceedings of the $4^{\text {th }}$ International Conference on Soil Mechanics and Foundation Engineering, 1957, London, England, 1: 200-206.

Svahn, P. O.; Alén, C. 2006. PKR 101, Transversalbelastade palar - statiskt verkningssatt och dimensioneringsanvisningar, IVA Palkommission.

Takahashi, K. 1985. Bending of a batter pile due to ground settlement, Soils and Foundations 25: 75-91. http://dx.doi.org/10.3208/sandf1972.25.4_75

Tomlinson, M. J.; Boorman, R. 2001. Foundation design and construction. Pearson education.

Wennerstrand, J.; Fredriksson, A. 1989. Capacity of slender steel piles, in Piling and Deep Foundations: Proceedings of the International Conference on Piling and deep Foundations, 15-18 May 1989, London, England. CRC Press.

Vermeer, P. A.; Neher, H. P. 1999. A soft soil model that accounts for creep, in Proceedings of the International Symposium, Beyond 2000 in Computational Geotechnics, 1999, Balkema, Rotterdam, 249-261. 